U.S. DEPARTMENT OF COMMERCE

National Institute of Standards and Technology

\title{
NISTIR 4629
}

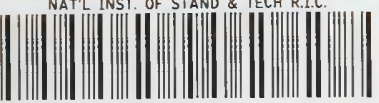

A】】I0ヨ 7】030

National PDES Testbed

Report Series

NIST

PUBLICATIONS

NATIONAL

Procedures and

System Requirements

\section{Configuration \\ Management of the STEP Documents:}

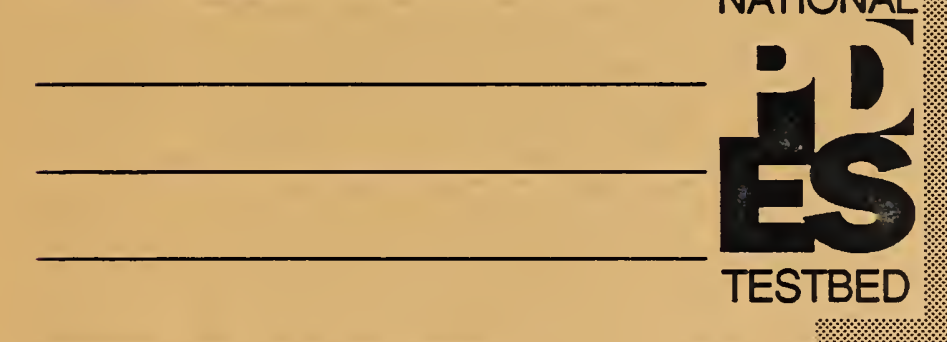

$-Q C$

100

.456

4629 



\section{NISTIR 4629}

\section{National PDES Testbed Report Series}

\begin{tabular}{l}
\hline U.S. DEPARTMENT OF \\
\hline COMMERCE \\
\hline Robert A. Mosbacher, \\
\hline Secretary of Commerce \\
\hline
\end{tabular}

National Institute of

Standards and Technology

John W. Lyons, Director

\section{Configuration Management of the STEP Documents:}

\section{Procedures and System Requirements}

\section{Susan Katz}

July 10, 1991 


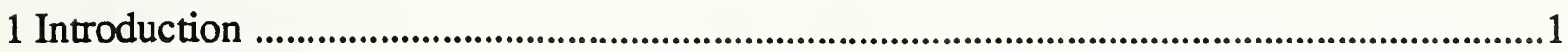

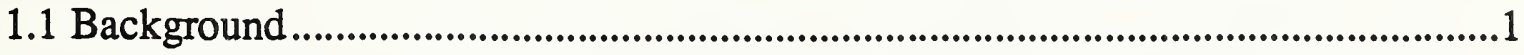

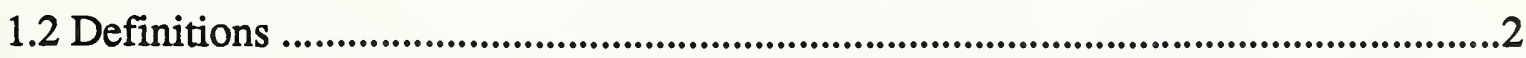

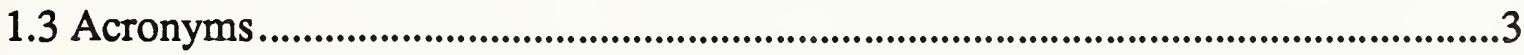

2 ISO Configuration Management Procedures .........................................................................3

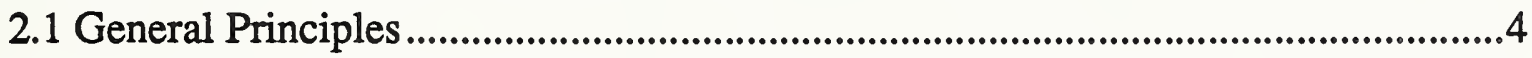

2.2 Initializing the Configuration Management System...................................................4

2.3 Overview of the Configuration Management Process ...............................................5

3 System Requirements ..............................................................................................................11

3.1 Access to the Configuration Management System .................................................11

3.2 Information Stored ..................................................................................................13

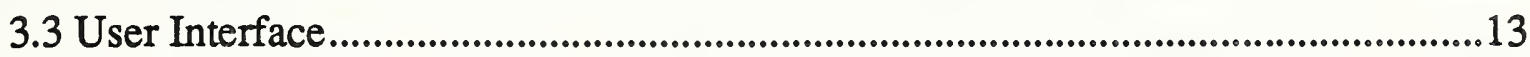

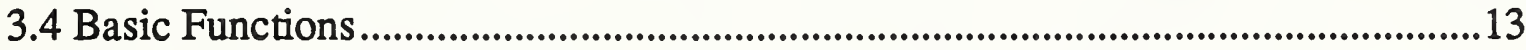

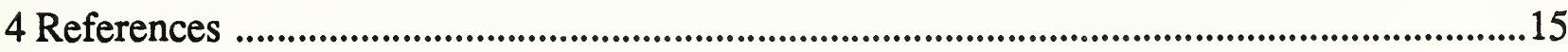




\section{Introduction}

The International Organization for Standardization (ISO) is currently involved in the development of a new international standard for the exchange of information related to automated manufacturing. The developing standard is informally called the Standard for The Exchange of Product Model Data (STEP). As the proposed standard progresses through the formal standards development process, the documents representing the continuing work must be placed under configuration management. The United States' effort in support of the standard is known as Product Data Exchange using STEP (PDES). The Information Services Center (ISC) within the National PDES Testbed Project at the National Institute of Standards and Technology (NIST) has taken on the task of providing a configuration management system in support of this ISO activity.

The purpose of this paper is first to propose configuration management procedures that support ISO's approval process for STEP, and second, to introduce requirements for incorporating those procedures into a configuration management system.

\subsection{Background}

Within ISO, the development of STEP is the responsibility of Technical Committee 184 (TC184), and, within that Technical Committee, it is assigned to SubCommittee 4 (SC4) [Smith1]. Within SC4, the Editing Committee is charged with the responsibility for configuration management. Also within SC4, there are numerous technical experts who are working on the content of the developing standard. These technical experts are grouped into Working Groups (WG's). The leader of each WG is called a Convener. Each WG is further broken down into Projects which address specific technical issues. All the WG's function under the coordination, planning and steering auspices of the Project Management Advisory Group (PMAG), which is also within SC4.

STEP is divided into Parts, or volumes. Each Part goes forward separately as a Committee Draft (CD). SC4 registers that CD within ISO. The CD then goes out for ballot, which means that it is sent to the National Bodies [IEC/ISO] for vote and review. (Each CD goes forward separately to become a Draft International Standard (DIS) and then an International Standard (IS). SC4 determines the collection of CD's that compose each version of STEP, to forward for DIS ballot.) The votes returned from the ballot may be accompanied by comments on how to improve the $C D$. There is already in place a standardized mechanism to collect these comments. Each comment must refer to at least one specific numbered section in a STEP Part. As used in this paper, a comment is any documented concern or issue. 


\subsection{Definitions}

Ballot Management: The process of logging and collating the ballot comments from a particular review cycle. This includes producing managerial summary reports.

Comment: A concern or issue that relates to at least one specific numbered section in a STEP Part.

Comment Database: A database containing the comments returned from a ballot process. These comments indicate requested changes to be made to the configured STEP documents.

Configuration Item: Any item being maintained within the configuration management system, that can be checked in or checked out as one unit. For ISO users, this would be a Part file or a comment.

Configuration Management System: The software which enables users to access files on a version by version basis in a controlled manner.

E-mail: Electronic mail.

File: see Part File.

Part: A specifically defined section of STEP, containing all the information about a particular subject. Each Part is defined by ISO TC184/SC4. Each Part goes through the same process as a standard, but the suite of Parts together composes STEP.

Part file: A computer file containing an electronic representation of a Part or a portion of a Part. The smallest unit of STEP uniquely identifiable in the configuration management system. The division of a Part into files is determined by the Part owner.

Part owner: The individual or group responsible for approving changes to a Part. When a Part is first assigned to a WG, the Part owner is the WG Convener. However, the WG Convener may then delegate Part ownership to a Project leader, and the Project leader may further delegate. A Part owner can ultimately be any properly authorized technical expert in charge of the development of a Part. Note that if a Part is broken up into several computer files, there may then be a separate owner for each Part file. The Part owner, as assigned by the WG Convener, is still responsible for the progression of the Part as a whole through each successive phase of the approval process.

Project: A group of technical experts working on a specific technical area. There may be multiple Projects within each Working Group (WG). A Project was formerly either a SubGroup(SG) or a sub-SubGroup. 
Signature authority: The authority to vouch for, and the responsibility for, the fact that proper procedures have been followed. Signature authority is specific to the particular phase being signed off on, and to the particular configured item in question.

\subsection{Acronyms}

CD: Committee Draft (formerly DP - Draft Proposal)

DIS: Draft International Standard

DP: Draft Proposal (now called CD - Committee Draft)

IGES: Initial Graphics Exchange Specification

IS: International Standard

ISC: Information Services Center

IPO: IGES/PDES Organization

ISO: International Organization for Standardization

NIST: National Institute of Standards and Technology

NPT: National PDES Testbed

PC: Personal Computer

PDES: Product Data Exchange using STEP

PDES, Inc.: a private industry consortium supporting the PDES effort

PMAG:Project Management Advisory Group

SC: Sub Committee

SG: SubGroup

STEP: Standard for the Exchange of Product Model Data

TC: Technical Committee

WG: Working Group

\section{ISO Configuration Management Procedures}

This section outlines a proposal for configuration management of STEP Parts. The phases described here all occur within the Preparatory Stage (Project Stage 2) of the ISO project stages (as defined in Table 1 in Section 2.1.1.1 of [IEC/ISO]). 


\subsection{General Principles}

STEP is divided into Parts, each addressing a separate technical area. The Project Management Advisory Group (PMAG) is responsible for assigning each STEP Part to a specific WG. SC4/Editing assigns ballot comments to the appropriate WG's for resolution. These assignments are worked out in conjunction with the WG Conveners.

Within the computerized configuration management system, each Part may be divided and stored in several different computer files, called Part files. A Part file is the smallest unit that can be checked out of the configuration management system. A user may also check out an entire Part at once.

Once either a Part or a comment has been assigned to a WG, the on-line version of that Part or comment comes under the ownership of the WG Convener. Ownership means that the owner controls write access to the computer file. Thus the owner of a Part (initially the WG Convener) can control all changes to that Part.

The configuration management system must track the ownership of each Part and its Part files. Thus if either Part ownership or Part file ownership change, the system must reflect that change in its future user interactions, must re-assign comments accordingly, and must keep track of which changes to the Part or Part file were made under which owner.

Actual changing of the contents of any Part file is the privilege of the Part file owner. Changes can be requested by coordinating Working Groups or by anyone involved in the phases of the review process, but they can only be implemented by the Part file owner. The original Part file owner may re-assign Part ownership in order to facilitate the change process.

Comments are initially assigned to the appropriate WG by the Editing Committee. However, if the WG Convener chooses to break the Part up into separate Part files, then the comments may be assigned accordingly. This will enable the user to check out a Part file and all the comments related to it.

The configuration management system allows for the break-up of Parts into Part files primarily for the convenience of the Working Groups; however, it should be noted that each Part goes through the phases of the approval process as a whole.

\subsection{Initializing the Configuration Management System}

In preparation for usage of the configuration management system, there are several things that must be done by each WG Convener. After having been assigned one or more Parts, each Convener must decide on the proper division of each Part into portions that are of suitable size and content for assignment to either individuals or ad hoc committees within that WG. The Convener can then grant signature authority and ownership of each Part file, if desired, to the individual working on each Part file. 
The Convener also receives comment assignments from SC4/Editing. The Convener may delegate comment ownership, and signature authority for comment status, to the owner of the affected Part file.

In conjunction with PMAG, the owning WG of each Part will come up with a coordination list. This list includes the names of related WG's which might have concerns about changes to this Part. Finally, the Convener should determine any other WG's documents for which this WG should be listed as a reviewer. The addition of such a "coordination signature" block to a comment or Part under configuration management will send an electronic mail message to the person whose coordination is being requested.

To initialize the system, existing ballot comments made against the Draft Proposal 1 for STEP (Dec. '88, also known as the Tokyo version [Smith2]) need to be mapped to the STEP Part documents to which they pertain. The STEP document number field on each comment record must be interpreted, in order to point to the proper document in the configuration management system. For instance, a comment that now points to paragraph 4.3.1.2 in Draft Proposal 1 may have to be modified to point to the appropriate location in the new version of STEP.

These preparations will support the coordination methods provided for in the configuration management process described in the following section of this paper.

\subsection{Overview of the Configuration Management Process}

The following process flow diagram and explanation depict the entire configuration management process as it relates to the STEP Parts and their associated comments. The phases described here all take place within the Preparatory Stage of the development of an international standard [IEC/ISO] [Smith1]. 


\section{Figure 1. STEP Documents Configuration Management Flow}

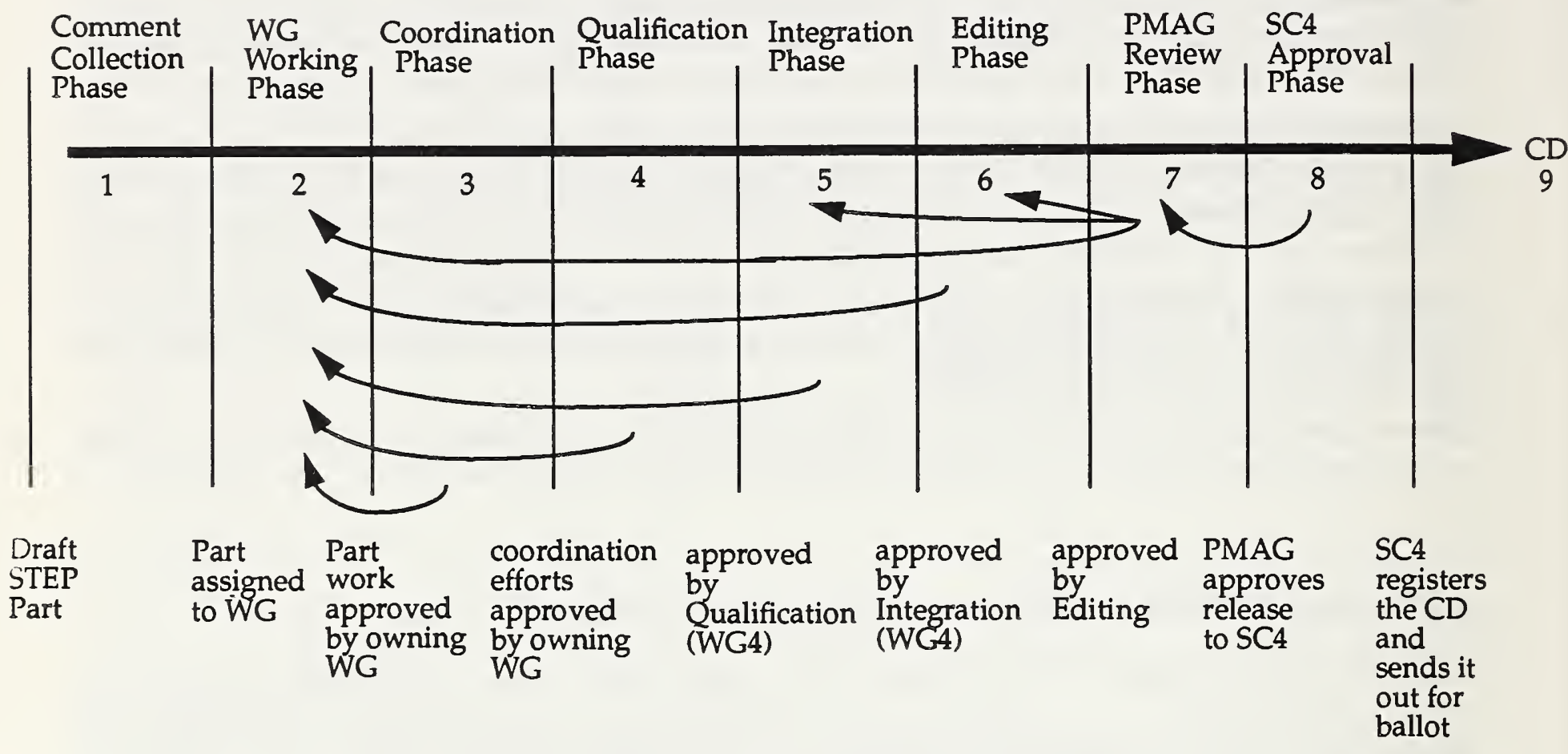

Notes:

- Each numbered Phase represents one to many versions of a STEP Part (including all of its Part files) that are stored on-line under the configuration management system.

- Each vertical bar represents the action necessary to promote the Part from one phase to the next.

- During each phase, the Part files may be checked in and out many times; however, the promotion points (vertical bars) pertain to the entire Part, and require appropriate signature authority.

- At any time during the life cycle of a Part, that Part may be returned to the owning WG for rework (e.g. if it is not approved by the Editing Committee). 
The following paragraphs provide an explanation of the phases pictured in the above process flow diagram.

\section{Comment Collection Phase}

This is the initial phase of managing a new draft STEP Part or an existing CD (before it goes out for ballot again).

Once the ballot comments for a particular Part have been collected, they are mailed to NIST on a diskette. At NIST, the comments are transferred to the computer where the main configuration management software resides.

ISO ballot comments are associated with separate portions of STEP. The configuration management system is responsible for maintaining the relationships between ballot comments and STEP Parts. Comments are checked in and out and worked on until a resolution is reached; then the comments are checked back in and the Part file itself is checked out for update. The system records the user's identification, and date/time when Part files or comments are checked out and when they are checked back in.

Each comment record has a status field to indicate the most recent status of the comment. After the comment has been resolved and the updated STEP file has been checked back in, the user checks out the comment and updates this status field. The comment owner's signature (WG Convener or appointee) is necessary for final comment resolution.

Once the Parts and corresponding comments are assigned by PMAG and Editing, they enter the WG Working Phase. At this point, the WG becomes the owner of the Part and its comments, and only the WG Convener, or a WG member with designated authority, can make changes to the Part file(s). In cases where ownership is reassigned, the configuration management system must be able to accommodate the proper tracking of this change.

The Comment Collection Phase is complete for a Part when that Part has been assigned to a WG. Comments may continue to be received, and they will be assigned to the appropriate Part(s), and forwarded to the WG(s) working on the Part(s).

\section{WG Working Phase}

Upon entering the WG Working Phase, the WG Convener or Project Leader obtains a list of the comments pertaining to each assigned Part. Note that at the Part level, the WG Convener is the owner of the STEP Part and its comments. However, the WG Convener may separate the Part into separate computer files, and may assign ownership of these files to individual WG members. Any comments associated with the particular file would also be assigned to that individual. Thus, at the file level, a file owner is an individual.

Each file and its comments can then be checked out for read-only purposes. It should be noted that any item under configuration management can be checked out for read-only purposes by any user at any time; however, update access is restricted to one authorized user at a time per configuration item. 
During the WG Working Phase, the file owner checks out the STEP file and its comments for read-only access, and decides upon resolutions for one or more of the comments. After the resolution has been decided upon, the owner checks out the STEP file and its comments for update purposes. This locks out any other users from updating that file for that period of time. Other users may, however, update comment status for comments which also pertain to other files. When the editing of the STEP file is complete, the owner will check the file back in, and at the same time submit an updated comment status for each comment resolved. Also at the same time, an explanation of the rationale for the resolution shall be added to the comment history.

At any time during the WG Working Phase, the actual editing and reviewing of changes to the STEP file may be done by an individual or by an ad hoc committee within the owning WG. Many check-outs and check-ins can occur: the users can store as many versions as they feel necessary under configuration management. For instance, each comment may be worked on separately.

The WG Convener is responsible for re-assembling any separate computer files into the complete Part.

The WG Working Phase is complete when the person with signature authority for that Part (WG Convener or Project Leader) signs off on the Part.

\section{Coordination Phase}

The purpose of the Coordination Phase is to expedite the integration process. The owning WG, in conjunction with the PMAG, comes up with a list of other WG's that may be affected by changes to this Part.

The Part enters the Coordination Phase when the owning WG or Project has completed its work on the Part to the point that it is ready for broader review. During the Coordination Phase, each Project on the coordination list may check out the Part (or its constituent files) and its comments for read-only purposes, and send feedback and/or a marked up hard copy version back to the owning Project. Note that during the entire process, only the file owner is allowed to enter changes to the STEP file itself.

Every check-out is recorded by the configuration management system. The passage from one phase to another is also recorded by the system, with the appropriate signature. Thus the progress of the Coordination Phase can be traced as the check-outs of files by people on the coordination list, done during the Coordination Phase.

The Coordination Phase is complete when the Part owner signs off on the coordination process. If a WG on the coordination list made suggestions that were not incorporated, they may send a minority report to PMAG. Any disagreements must be worked out during the Integration Phase, under the guidance of the Qualification and Integration WG (formerly the Integration Committee). 


\section{Qualification Phase}

After the owning WG has signed off on the Coordination Phase, the Part enters the Qualification Phase. During the Qualification Phase, the Qualification and Integration WG (WG4) subjects the Part to a pre-defined set of qualification requirements. These requirements will vary depending on the basic category of information contained in the Part, and its technical area. Members of the Qualification and Integration WG may check out any STEP file and its comments for read-only purposes, but any actual changes to the STEP file must be made by the owning WG. If a Part does not meet the qualification requirements, it goes back to the WG Working Phase.

The Qualification Phase is complete when the WG4 Convener signs off on the set of qualification requirements for that Part.

\section{Integration Phase}

After the owning WG has signed off on the Qualification Phase, the Part enters the Integration Phase. During the Integration Phase, the Qualification and Integration WG, must verify that the changes to the Part have been coordinated and agreed upon by all the appropriate parties. The Qualification and Integration WG Convener has signature authority for the completion of the Integration Phase. Members of the Qualification and Integration WG may check out any STEP file and its comments for read-only purposes, but any actual changes to the STEP file must be made by the owning WG. If a Part does not pass integration, it goes back to the WG Working Phase.

The Integration Phase is complete when the WG Convener of the Qualification and Integration Working Group signs off on the integration process.

\section{Editing Phase}

During the Editing Phase, the integrated Part undergoes editorial checking by the Editing Committee.

This phase serves as the final of the editing of a Part before it goes to PMAG for review. It is not, however, the only time the Editing Committee reviews the Part. In fact, each time the Part is checked back in to the configuration management system, the chair of the Editing Committee is notified automatically by electronic mail. This allows editorial changes to be incorporated as the Part develops.

During each review, the Editing Committee produces a marked up hard copy version, which is returned to the owning WG for the corrections to be made. This is to avoid the possibility that an editorial change may inadvertently change the technical meaning of the Part. Any disagreements about wording must be worked out between the owning WG and the Editing Committee during this phase. When the Part is approved by the Editing Committee, it can then progress to the next phase. If a Part does not pass Editing, it goes back to the WG Working Phase. Any changes made to the Part by the owning WG must be reviewed by the Integration WG as well as the Editing WG. 
The Editing Phase is complete when the chair of the Editing Committee signs off on the completed Part.

\section{PMAG Review Phase}

The purpose of the PMAG Review Phase is for PMAG to review the final, edited Part and make a decision about its release to SC4. PMAG can send the Part back to any phase in the process if it recommends reworking the Part. If a Part does go back to an earlier phase, it must go through all the succeeding phases again. For instance, if PMAG determines that the Part was not adequately integrated, it would send it back to the Integration Phase. The Qualification and Integration WG might then require integration with an additional WG. Any changes suggested would have to be reviewed and implemented by the owning WG. If the changes were in fact incorporated, then the Part would have to progress again through the Integration and Editing phases before returning to the PMAG Review Phase. Similarly, any changes requested by the Editing Committee must be coordinated with the Qualification and Integration Working Group. The PMAG Review Phase is complete when the Part is approved by a vote of the PMAG membership. An approved Part is sent by the SC4 Secretariat to ISO for registration as a $\mathrm{CD}$.

\section{SC4 Approval Phase}

ISO registers each approved Part as a CD and the SC4 Secretariat distributes it to the SC4 voting members for consensus approval. SC4 determines the collection of Parts which will go forward as the next version of STEP. If SC4 does not approve a Part, the Part is sent back to the PMAG Review Phase, and PMAG must determine the proper course for corrections (see PMAG Review Phase, above).

The SC4 Approval Phase is complete when the Part is registered as a CD.

\section{Committee Draft (CD)}

The registered $C D$ is ready to enter the next ballot process. 


\section{System Requirements}

The objectives of providing a computerized configuration management system are:

- to provide fixed checkpoints in the standard's development process

- to provide a centralized place to obtain the latest versions of official documents

- to provide clear procedures and mechanisms for formal coordination between the various technical experts and committees

- to obtain current status of comments.

General requirements for the configuration management system, as they relate to ISO procedures, are outlined here. A more comprehensive view of system requirements is provided in the "Configuration Management Comprehensive Requirements Document" [Katz1].

\subsection{Access to the Configuration Management System}

Access to the Draft Proposal 1 of STEP ("Tokyo version")[Smith2], as well as newer versions, as they are provided to NIST, is already available through the STEP On-Line Information Service [Katz2]. This service allows users to view and make copies of one central, complete set of the latest STEP Parts. Access to the service is provided through a BBS (Bulletin Board System) via modem, and through ftp (file transfer protocol) via Internet. An electronic mail interface is provided as well, and is described in "The National PDES Testbed Mail Server User's Guide" [Ressler2].

The STEP On-Line Information Service provides read-only copies only. In order to submit new information, a user must provide a machine-readable version to the NIST Configuration Management Administrator.

The final CM system will allow both uploading and downloading of computer files, based on the appropriate user authorization. The development of the configuration management system is described in the "Configuration Management Systems and Services Development Plan" [Ressler1].

There are three ways to access the configuration management system: E-mail, Internet (network) and modem (see Figure 2. on page 10). Each method can be accomplished from either a terminal or a PC. 
Configuration Management of the STEP Documents: Procedures and System Requirements

Figure 2. Functional View of the Configuration Management System

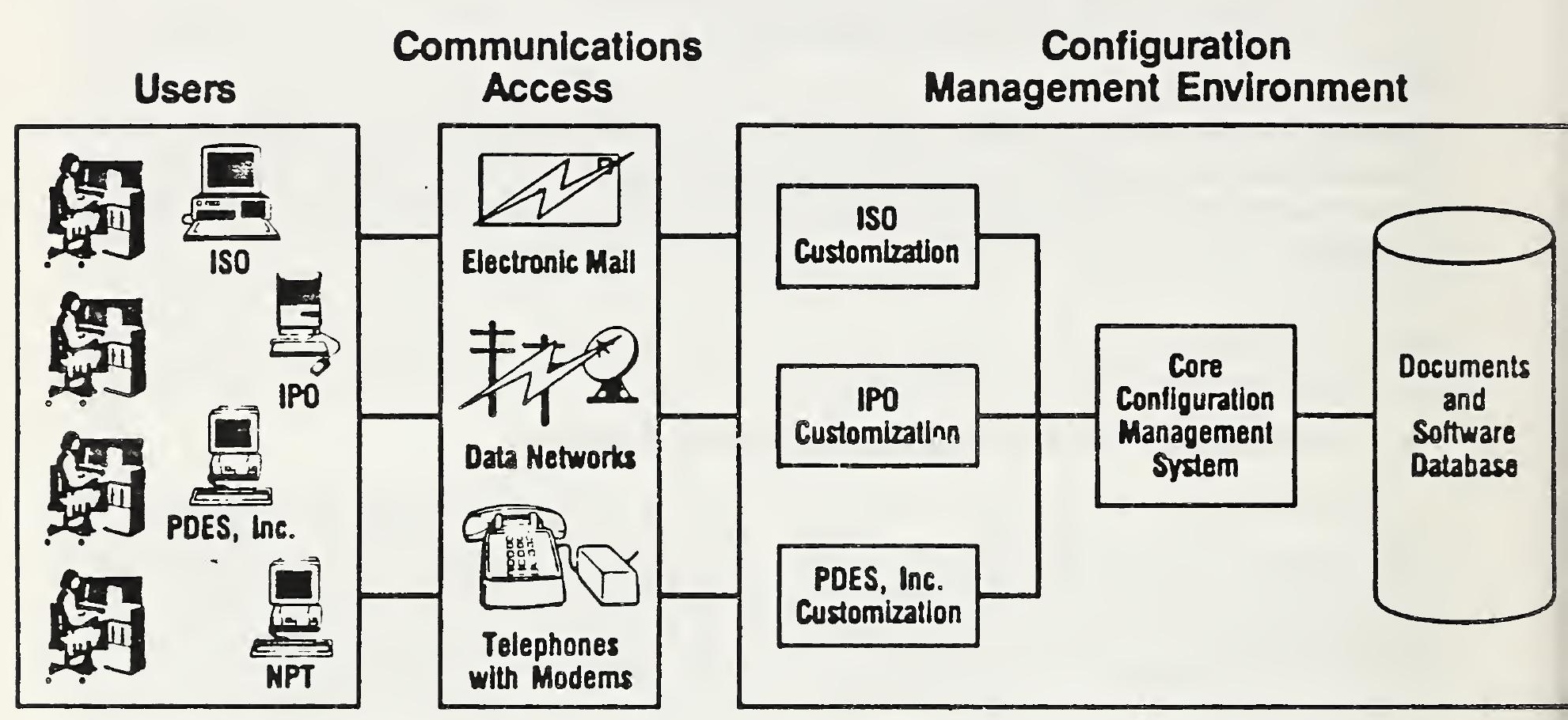




\subsection{Information Stored}

The information stored in the computerized configuration management system shall include:

- text of each version of each STEP Part file

- ballot comments, and for each ballot comment:

- numbered section of STEP to which it pertains

- comment owner

- status, date, time and user identification for each time status was updated

- list of authorized users, including which users have signature authority for which tasks

- list of which computer file(s) compose each STEP Part

- the owner of each STEP Part file

- the coordination list for each Part

- sign-off date, time and user identification for each phase

\subsection{User Interface}

No formal training is required for a user to access the system immediately to determine the documents available, generate reports and initiate file transfers.

\subsection{Basic Functions}

\section{Reporting}

The user will be able to list the documents available from the configuration management system. The list will reflect the hierarchy of the STEP Part files, as stored on-line. The online version of the document names will be needed for submitting other commands to the system.

The user will be able to obtain a list of all the comments against a particular STEP Part file, and, if desired, their status.

It will be possible for any user to obtain a report of which documents and comments are currently checked out. This report will show, for each item, whether the item is checked out for read or update purposes, the user identification of each checkout, and the time of each checkout.

It will be possible for any user to obtain the checkout history of any item under configuration management. This report will be able to be produced for any of the following combinations as well:

- a Part and its related comments

- a particular comment 
- all the comments

- all the Parts.

Reporting capability shall include the ability to list the history of changes to a document, including the content of the changes, who made each change when and why (there shall be a required "reason for change" field associated with each new version of a document).

\section{Check - In and Check - Out}

Any user will be able to check out, for read only purposes, any Part file or comment in the system.

A user will be able to check out either an entire Part, or any one of its constituent Part files, with one command.

Only a user specified as a Part file owner may check out that Part file, or the comments against it, for update purposes. When any item is checked out for update purposes, it is locked to all other users in the system except for read-only access.

The system will be able to produce any version of a Part or Part file, or list just the changes from one version to the next.

The system will record the date, time, and user identification both when a STEP Part file is signed out for update and when it is signed back in. Files checked out for read only purposes need not be checked back in.

The system will maintain a historical log related to each comment. When a comment status is changed, the date, time, user identification and a user-provided explanation will be appended to the comment history. A comment may pertain to multiple Part files, or even to multiple STEP Parts. In this case, every user who is the owner of a pertinent Part file will have write access to the comment history.

\section{Version Promotion}

When a STEP file progresses from one phase to the next in the configuration management flow, the system will require the proper user identification. The user identification and the date and time of the promotion will be recorded. Each time a file is promoted from one phase to the next, the system will notify the chair of the Editing Committee by electronic mail. The editors can then check out a read-only copy to review.

\section{Summary}

This paper has presented a proposal for the STEP Part approval process, and introduced the requirements for incorporating that process into a configuration management system. To the extent possible, as changes are made in the ISO TC184/SC4 procedures, the configuration management system will be modified to accommodate those changes. 


\section{References}

[IEC/ISO] IEC/ISO Directives, International Electrotechnical Commission, Geneva, Switzerland, and International Organization for Standardization, Geneva, Switzerland, 1989.

[ISO]

Product Data Representation and Exchange - Parts $1-205^{1}$, ISO TC184/ SC4, DP 10303-1 through DP 10303-205 (to be published).

[Katz1] Katz, Susan, Configuration Management Concepts Document, NISTIR 4538, National Institute of Standards and Technology, Gaithersburg, MD, April, 1991.

[Katz2] Katz, Susan, STEP On-Line Information Service User's Guide, NISTIR 4491, National Institute of Standards and Technology, Gaithersburg, MD, January, 1991.

[Ressler1] Ressler, Sandy and Katz, Susan, Development Plan, Configuration Management Systems and Services, NISTIR 4413, National Institute of Standards and Technology, Gaithersburg, MD, September, 1990.

[Ressler2] Ressler, Sandy, The National PDES Testbed Mail Server User's Guide, NISTIR 4508, National Institute of Standards and Technology, Gaithersburg, MD, January, 1991.

[Smith1] Smith, Bradford, Policy and Procedures Manual for the ISO TC 184/ SC4 Subcommittee, ISO TC184/SC4, February, 1991.

[Smith2] Smith, Bradford, and Rinaudot, Gaylen, Product Data Exchange Specification: First Working Draft, NISTIR 88-4004, December, 1988.

1. Informally called "STEP"; ISO number 10303-n, where $n$ is the Part number. 


\section{-}




\section{NIST-114A}

(REV. 3-90)
U.S. DEPARTMENT OF COMMERCE NATIONAL INSTITUTE OF STANDARDS AND TECHNOLOGY

\section{BIBLIOGRAPHIC DATA SHEET}

1. PUBLCATION OR REPORT NUMBER

NISTIR 4629

2. PERFORMING ORGANIZATION REPORT MUMBER JULY 1991

3. PUBLICATION DATE

\section{TITLE AND SUBTITLE}

Configuration Management of the STEP Documents: Procedures and System Requirements

5. AUTHOR(S)

Susan B. Katz

6. PERFORMING ORGANIZATION (IF JOINT OR OTHER THAN NIST, SEE INSTRUCTIONS)

U.S. DEPARTMENT OF COMMERCE

MATIONAL INSTITUTE OF STANDARDS AND TECHNOLOGY

GATHERSBURQ, MD $20899^{\circ}$

7. CONTRACT/GRANT NUMBER

8. TYPE OF REPORT AND PERIOD COVERED

9. SPONSORING ORGANIZATION MAME AND COMPLETE ADDRESS (STAEET, CITY, STATE, ZIP)

Office of the Secretary of Defense

CAIS Program Office

Pentagon

Washington, DC 20301-8000

10. SUPPLEMENTARY NOTES

11. ABSTRACT (A 200-WORD OR LESS FACTUAL SUMMARY OF MOST SIGMIFICANT INFORMATION. IF DOCUMENT INCLUDES A SIGNIFICANT BIBUOGRAPHY OR UTERATURE SURVEY, MENTION IT HERE)

The purpose of this paper is to first propose configuration management procedures that support ISO's approval process for STEP, and second, to introduce requirements for incorporating those procedures into a configuration management system.

12. KEY WORDS (6 TO 12 ENTRIES; ALPHABETICAL ORDER; CAPITALZE ONLY PROPER NAMES; AND SEPARATE KEY WORDS BY SEMICOLONS)

Configuration Management; CM, ISO; STEP; PDES; document management

13. AVAILABIITTY

C

\section{UNLMITED}

FOR OFFICIAL DISTAIBUTION. DO NOT RELEASE TO NATIONAL TECHMICAL INFORMATION SERVICE (NTIS).

ORDER FROM SUPERINTENDENT OF DOCUMENTS, U.S. GOVERNMENT PRINTING OFFICE, WASHINGTON, DC 20402.

ORDER FROM NATIONAL TECHNICAL MFORMATION SERVCE (NTIS), SPRHOFIELD, VA 22161.
14. NUMBER OF PRINTED PAGES

] 9

15. PRICE

$\mathrm{A03}$ 


